\title{
Efektifitas Perlindungan Kawat Tanah Jaringan SUTM 20 kV Gardu Induk Boom Baru Palembang
}

\author{
Wiwin A. Oktaviani, Indah Permata Hati \\ Teknik Elektro Universitas Muhammadiyah Palembang \\ Jln. Jendral Ahmad Yani 13 Ulu Palembang \\ winarvin1302@gmail.com
}

\begin{abstract}
Abstrak-Jaringan SUTM seringkali mengalami gangguan petir tak langsung berupa sambaran induksi. Hal ini disebabkan tingkat ketahanan impuls isolasi $V_{50 \%}$ dari isolator SUTM relative rendah. Untuk itu kawat ditempatkan pada jaringan untuk perlindungan. Efektifitas perlindungan kawat tanah dinyatakan sebagai faktor perisaian yang didefinisikan sebagai hasil bagi tegangan induksi dengan kawat tanah dan tegangan induksi tanpa kawat tanah.Tujuan penelitian ini adalah untuk mengetahui tingkat efektifitas kawat tanah dalam melindungi kawat saluran pada SUTM 20 kV di Gardu Induk Boom Baru. Dari hasil perhitungan dan analisa bahwa nilai faktor perisaian kawat tanah di Gardu Induk Boom Baru sudah cukup efektif, karena mampu mengurangi jumlah gangguan petir induksi sebesar 35,50 gangguan per $100 \mathrm{~km}$ per tahun
\end{abstract}

Kata kunci : petir; sambaran induksi; sambaran langsung; kawat tanah

\section{PENDAHULUAN}

Pengaruh sambaran petir pada jaringan SUTM lebih disebabkan oleh sambaran tak langsung. Hal ini disebabkan karena saluran udara tegangan menengah tidak begitu tinggi diatas tanah, yang mengakibatkan resiko tersambar langsung lebih rendah. Ditambah lagi tingkat ketahanan impuls isolasi $\left(\mathrm{V}_{50 \%}\right)$ dari isolator SUTM relatif rendah bila dibandingkan dengan SUTT [1]. Sambaran induksi terjadi bila petir menyambar area sekitar saluran sehngga menimbulkan fenomena transien yang diakibatkan oleh medan elektromagnetis dari kanal petir. Untuk mengurangi dampak dari induksi dari sambaran tak langsung tersebut pada jaringan SUTM ditempatkan kawat tanah. Efektifitas perlindungan kawat tanah dinyatakan sebagai Faktor Perisaian (FP) yang didefinisikan sebagai hasil bagi tegangan induksi dengan kawat tanah dan tegangan induksi tanpa kawat tanah. Pada penelitian ini, perhitungan faktor perisaian dilakukan secara manual. hasil yang didapatkan berupa tingkat efektifitas perlindungan kawat tanah terhadap jaringan SUTM $20 \mathrm{kV}$ dengan menghitung nilai faktor perisaian dan jumlah gangguan petir [2].

Gardu Induk Boom Baru merupakan gardu induk lama dan telah ada sejak jaman perang kemerdekaan. Karenanya beberapa bagian distribusi tegangan $20 \mathrm{kV}$ masih menggunakan kawat tanah sebagai salah satu proteksi terhadap dampak induksi sambaran.

\section{TINJAUAN PUSTAKA}

Gangguan petir pada saluran udara tegangan menengah dibedakan menjadi dua macam yaitu sambaran langsung dan sambaran tak langsung (induksi).

Sambaran langsung adalah petir yang menyambar langsung pada kawat fasa (untuk saluran tanpa kawat tanah) atau pada kawat tanah (untuk saluran dengan kawat tanah) .

Sambaran tidak langsung (induksi) dapat terjadi karena [3]:

1. Induksi elektromagnetik (arus) akibat terjadinya pelepasan muatan di dekat sistem.

2. Induksi elektrostatis sebagai akibat adanya awan bermuatan di atas hantaran udara.

Bila petir menyambar ke tanah di dekat saluran, akan terjadi fenomena transien yang diakibatkan oleh medan elektromagnetis dari kanal petir terjadi pada kawat penghantar. Akibatnya timbul tegangan lebih dan gelombang berjalan yang merambat pada kedua sisi kawat di tempat sambaran berlangsung [3].

A. Teori Kawat Tanah

Kawat tanah atau kawat perisai (shielding wire) merupakan kawat-kawat pada saluran yang ditempatan di atas kawatkawat fasa sebagai perlindungan terhadap sambaran induksi petir di sekitar saluran. Jika terjadi sambaran petir ke jaringan distribusi tegangan menengah, kawat tanah akan mengalirkan arus surja petir ke tanah sehingga jaringan tegangan menengah bebas dari gangguan [4]. Kawat tanah hendaknya memiliki tahanan kontak yang rendah namun ketahanan impuls isolasinya tinggi.

B. Pengaruh kawat tanah terhadap tegangan induksi

Efektifitas perlindungan kawat tanah terhadap tegangan induksi dinyatakan sebagai Faktor Perisaian (FP) yang didefinisikan sebagai hasil bagi tegangan induksi dengan kawat tanah dan tegangan induksi tanpa kawat tanah.

Kawat tanah ideal adalah kawat tanah yang mempunyai potensial sepanjang kawat sama dengan nol. Untuk mencapai hal tersebut maka diperlukan titik 
pentanahan di sepanjang kawat tanah. Akan tetapi kondisi ini tidak ekonomis untuk diterapkan sehingga, sehingga pentanahan kawat tanah ditempatkan pada titik-titik tertentu saja [5]. Pada saluran udara tegangan menengah tidak semua tiang di ketanahkan, tetapi selang 3 sampai 4 gawang. Akibatnya kawat tanah akan mempunyai beda tegangan tertentu terhadap tanah. Panjang gawang antara 40 sampai 80 meter, sehingga semua sambaran dapat diasumsikan mengenai tiang, baik tiang yang ketanahkan maupun tiang yang tidak di ketanahkan [6]. Tiang yang di ketanahkan mempunyai tahanan kontak 20 ohm sedangkan tiang yang tidak diketanahkan nilai tahanan kontaknya tinggi, beberapa ratus sampai ribuan ohm, tergantung dari jenis pondasi dan keadaan tanah [7].

Gambar 1 menunjukkan keadaan sebuah kawat tanah ditempatkan di atas kawat fasa. Tahanan kontak tiang sebesar $R$. Diasumsikan tidak terjadi pantulan pada ujung saluran. Bila gelombang tegangan yang timbul pada kawat 2 (kawat tanah) sebelum diketanahkan adalah $\mathrm{V}_{2}$, maka arus yang melalui impedansi setelah diketanahkan dengan tahanan $R$ sebesar :

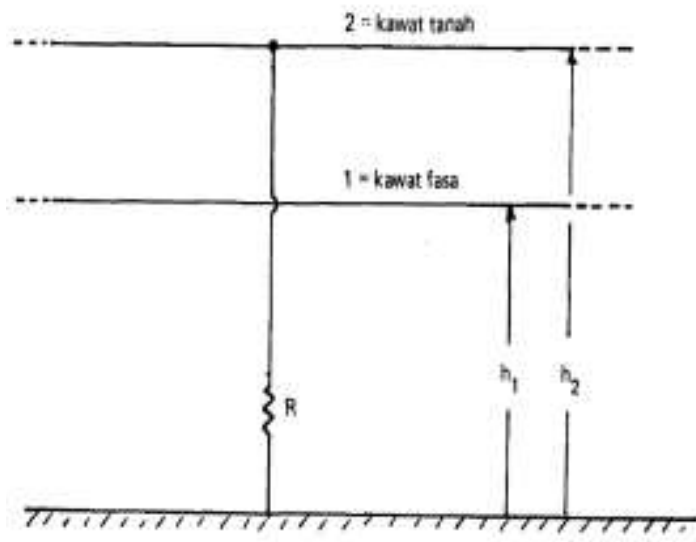

Gambar 1. Saluran dengan satu kawat tanah

$$
I_{2}=\frac{V_{2}}{R+\left(Z_{22} / 2\right)}
$$

dengan :

$$
\begin{aligned}
V_{2}= & \text { tegangan induksi pada kawat tanah sebelum di } \\
& \text { ketanahkan } \\
Z_{22}= & \text { impedansi surja kawat } 2 \\
R= & \text { tahanan kontak ketanah } \\
I_{2}= & \text { arus yang mengalir pada hubungan ke tanah. }
\end{aligned}
$$

Arus $\mathrm{I}_{2}$ menyebabkan kenaikan pada gelombang tegangan pada kawat fasa sebesar:

$$
\Delta V_{2}=Z_{12}\left(-\frac{I_{2}}{2}\right)=-\frac{Z_{12}}{2 R+Z_{22}} V_{2}
$$

Dengan demikian besarnya tegangan pada kawat fasa setelah kawat tanah diketanahkan adalah :

$$
\begin{aligned}
& V_{1}^{\prime}=V_{1}^{0}+\Delta V_{2} \\
& V_{1}^{\prime}=V_{1}-\frac{Z_{12}}{2 R+Z_{22}} V_{2}
\end{aligned}
$$

Nilai Faktor Perisaian (FP) didapat dengan membandingkan nilai tegangan kawat fasa sebelum dan sesudah kawat tanah diketanahkan.Secara matematis dirumuskan sebagai berikut :

$$
F P=\frac{V_{1}^{\prime}}{V_{1}}=1-\frac{Z_{12}}{2 R+Z_{22}} \frac{V_{2}}{V_{1}}
$$

$V_{1}{ }^{\prime}=$ tegangan induksi pada kawat fasa setelah kawat tanah diketanahkan.

$V_{1}=$ tegangan induksi pada kawat 1 sebelum kawat tanah diketanahkan.

Besarnya tegangan induksi sebelum diketanahkan sebanding dengan tinggi kawat diatas tanah, atau $\left(V_{2} / V_{l}\right)=$ $\left(h_{2} / h_{l}\right)$, maka Faktor Perisaian menjadi,

$$
F P=\left(1-\frac{Z_{12}}{2 R+Z_{22}} \frac{h_{2}}{h_{1}}\right)
$$

dan,

$$
V_{1}^{\prime}=\left(\begin{array}{ll}
1-\frac{Z_{12}}{2 R+Z_{22}} & \frac{h_{2}}{h_{1}}
\end{array}\right) V_{1}
$$

$$
\begin{aligned}
& \text { dengan: } \\
& V_{1}{ }^{\prime}=\text { tegangan induksi pada kawat fasa dengan kawat } \\
& \quad \text { tanah }(\mathrm{kV}) \\
& V_{1}=\begin{array}{l}
\text { tegangan induksi pada kawat fasa tanpa kawat } \\
\text { tanah }(\mathrm{kV})
\end{array} \\
& Z_{22}=\text { impedansi surja sendiri kawat tanah } 2(\mathrm{ohm}) \\
& Z_{12}=\text { impedansi surja bersama antara kawat tanah } 2 \\
& \quad \text { dan kawat fasa } 1 \text { (ohm) } \\
& h_{1}=\text { tinggi rata-rata kawat fasa di atas tanah }(\mathrm{m}) \\
& h_{2}=\text { tinggi rata-rata kawat tanah di atas tanah }(\mathrm{m}) \\
& R=\text { tahanan kontak ke tiang (ohm). }
\end{aligned}
$$

Besarnya impedansi surja sendiri kawat tanah $\left(\mathrm{Z}_{22}\right)$ diberikan pada persamaan berikut:

$$
\begin{aligned}
\mathrm{Z}_{11} & =\mathrm{Z}_{22}=\mathrm{Z}_{\mathrm{g}} \\
Z_{22} & =60 \ln \left(\frac{2 h_{t}}{r}\right)
\end{aligned}
$$

Dengan :

$Z_{22}=$ impedansi surja kawat tanah

$\mathrm{h}_{\mathrm{t}}=$ tinggi kawat tanah

$\mathrm{r}=$ jari - jari konduktor kawat tanah

Sedangkan untuk impedansi surja bersama kawat tanah dengan kawat fasa $\left(Z_{12}\right)$ adalah,

$$
Z_{12}=60 \ln \left(\frac{a_{1}^{\prime}}{a_{1}}\right)
$$




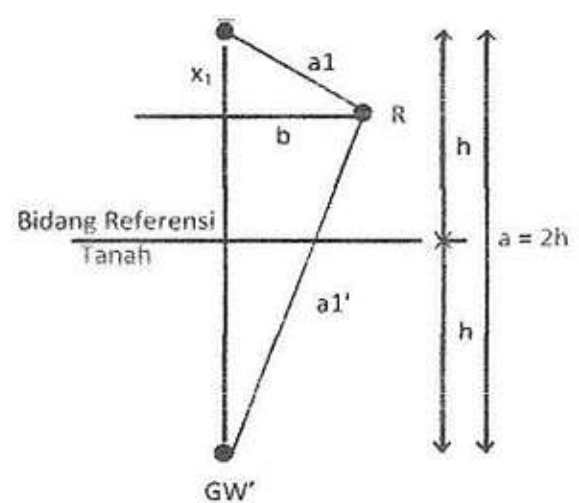

Gambar 2.Hubungan antara kawat tanah dan bayangannya

Nilai $\mathrm{a}_{1}$ dan $\mathrm{a}_{1}$ ' ditentukan dengan memperhatikan gambar 2. Kawat tanah akan memiliki bayangannya, GW' dengan permukaan tanah sebagai bidang referensinya. Untuk mencari $a_{1}$ dan $a_{1}^{\prime}$ diberikan pada persamaan berikut :

$$
\begin{gathered}
\mathrm{a}_{1}=\sqrt{x_{1}^{2}+\mathrm{b}^{2}} \\
\mathrm{a}_{1}^{\prime}=\sqrt{\left(a-x_{1}\right)^{2}+\mathrm{b}^{2}}
\end{gathered}
$$

dengan :

$a=2 \mathrm{~h}$

$\mathrm{h}=$ tinggi kawat tanah

$x_{1}=$ tinggi antara kawat fasa dan kawat tanah.

$b=$ setengah jarak antar kedua kawat fasa

C. Perhitungan Jumlah Gangguan Petir Akibat Sambaran Induksi

Lompatan api yang timbul tidakserta merta beralih menjadi busur api atau gangguan. Besarnya gangguan tergantung dari besar probabilitas peralihan lompatan api menjadi busur api, $\eta$. Besarnya nilai $\eta=0,5$ dan ketahanan impuls isolasi $V_{50 \%}=160 \mathrm{kV}$ [8]. Dengan demikian jumlah gangguan petir akibat sambaran induksi (gangguan per 100 km per tahun) diberikan oleh persamaan :

- untuk satu kawat tanah

$$
N_{i}=30,6 \cdot I K L \cdot F P \cdot h_{t} \cdot \frac{e^{-\left(\frac{V 50 \%}{510 \cdot F P} \cdot h^{0.09}\right)}}{V 50 \%} x \eta
$$

- tanpa kawat tanah:

$$
N_{i}=30,6 \cdot I K L \cdot h \cdot \frac{e^{-\left(\frac{V 50 \%}{510} \cdot h^{0.09}\right)}}{V 50 \%} x \eta
$$

dengan:

$I K L=$ jumlah hari guruh per tahun

$h=$ tinggi kawat fasa diatas tanah, $(\mathrm{m})$

$h_{t}=$ tinggi kawat tanah diatas tanah, (m)

$\eta=$ probabilitas peralihan lompatan api menjadi busur api Satuan
D. Perhitungan Jumlah Gangguan Petir Akibat Sambaran Langsung

Bila saluran tanpa kawat tanah, probabilitas terjadinya lompatan bunga api dirumuskan sebagai berikut :

$$
P_{F L}=e^{-\left(\frac{V_{50 \%}}{8,5 Z_{p}}\right)}
$$

Untuk saluran menggunakan kawat tanah tanah, probabilitas terjadinya lompatan bunga api adalah :

$$
P_{F L}=e^{-\left(\frac{V_{50 \%}}{\left(R+\delta \cdot h_{t} \cdot 34\right.}\right)}
$$

dengan :

$\mathrm{Z}_{\mathrm{p}}=$ impedansi surja kawat

$\delta=0,3$ untuk satu kawat tanah;

0,15 untuk dua kawat tanah

Sedangkan jumlah sambaran petir pada saluran dinyatakan sebagai berikut :

$$
N_{t}=0,015 \cdot I K L \cdot\left(b+4 \cdot h^{1.09}\right) \cdot P_{F L} x \eta
$$

E. Daerah Perisaian

Suatu saluran di atas tanah akan membentuk daerah bayang-bayang listrik pada tanah di bawah saluran. Daerah ini disebut daerah perisaian. Petir yang biasanya menyambar tanah di dalam daerah perisaian akan menyambar / menginduksi saluran distribusi, sedang petir di luar bayang-bayang itu tidak menyambar/menginduksi saluran. Whitehead (1977) telah merumuskan persamaan untuk menghitung lebar daerah bayang-bayang listrik atau daerah perisaian itu sebagai berikut [8]:

$$
W=\left(b+4 h^{1,09}\right) \text { meter }
$$

Di mana,

$b=$ jarak pemisah antara kedua kawat tanah (meter, bila kawat tanah hanya satu, $b=0$ )

$h=$ tinggi rata-rata kawat tanah di atas tanah

$=\mathrm{h}_{\mathrm{t}}-\frac{2}{3}$ andongan (meter).

$h_{t}=$ tinggi kawat tanah pada tiang (meter).

Di luar daerah perisaian itu petir dianggap menyambar langsung ke tanah, atau disebut sambaran induksi. Pada saluran udara tegangan menengah (SUTM) lebar bayang-bayang untuk tiga macam konfigurasi diberikan pada gambar 3 berikut: 



Gambar 3. Lebar bayang-bayang listrik [9]

(a) Saluran udara tanpa kawat tanah

(b) Saluran udara dengan kawat netral $n(b=0)$

(c) Saluran udara dengan satu kawat tanah $(b=0)$

Sudut pengamanan kawat tanah erkisar antara $25^{\circ}$ hingga $55^{0}$ (dapat dilihat pada gambar 4). Dari gambar tersebut, jika kawat tanah diletakkan setinggi h meter dari cross arm tiang, maka daerah proteksi sistem kawat tanah terletak di dalam daerah segitiga. Jika kawat phasa ditempatkan di dalam zona tersebut, kawat fasa akan dapat terlindungi dari sambaran petir langsung.



Gambar 4. Daerah perlindungan dengan kawat tanah [8]

Andongan atau sag adalah merupakan jarak lenturan suatu bentangan kawat diantara dua tiang penyangga (gambar 5). Berat, panjang kawat penghantar dan jarak antar tiang (span) mempengaruhi nilai lenturan kawat penghantar tersebut [10].

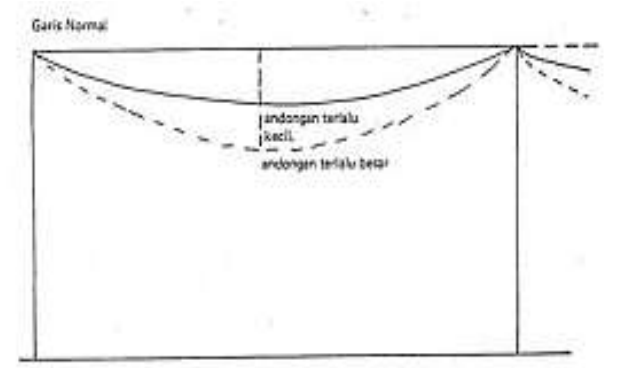

Gambar 5. Andongan atau sag pada kawat tanah
Andongan dihitung dengan menggunakan persamaan berikut :

$$
D=\frac{w d^{2}}{8 t}
$$

Dengan :

$$
\begin{aligned}
& \mathrm{D}=\text { andongan } \\
& \mathrm{w}=\text { berat kawat dalam } \mathrm{kg} / \mathrm{m} \\
& \mathrm{d}=\text { jarak antar tiang }
\end{aligned}
$$

\section{METODE PENELITIAN}

Untuk menghitung sejauh mana efektifitas kawat tanah melindungi SUTM $20 \mathrm{kV}$ GI Boom Baru, terlebih dulu dihitung impedansi surja sendiri kawat tanah dan impedansi surja bersama kawat tanah dan kawat fasa. Selanjutnya hasil yang didapat digunakan untuk menghitung jumlah gangguan petir baik akibat induksi maupun sambaran langsung serta lebar daerah perisaian kawat tanah. Tahapan penelitian digambarkan pada Gambar 7 berikut :



Gambar 6. Diagram Alur Penelitian

\section{HASIL DAN PEMBAHASAN}

Data kawat tanah untuk jaringan SUTM 20 kV GI Boom Baru Palembang dapat dilihat pada tabel 1 berikut :

Tabel.1 Spesifikasi tiang SUTM $20 \mathrm{kV}$

\begin{tabular}{lc}
\hline \multicolumn{1}{c}{ Spesifikasi } & Nilai \\
\hline Tinggi rata-rata kawat fasa diatas tanah & $8,9 \mathrm{~m}$ \\
\hline Tinggi kawat tanah diatas tanah & $10 \mathrm{~m}$ \\
\hline Jarak vertikal kawat tanah dan kawat fasa & $1,1 \mathrm{~m}$ \\
\hline Kedalaman tiang & $2 \mathrm{~m}$ \\
\hline Jarak antara kedua kawat fasa & $3,6 \mathrm{~m}$ \\
\hline Diameter Kawat Tanah & $50 \mathrm{~mm}$ \\
\hline
\end{tabular}




\begin{tabular}{lc}
\hline Jenis kawat tanah & BC \\
\hline Berat kawat tanah & $0,447 \mathrm{~kg} / \mathrm{m}$ \\
\hline Regangan mendatar kawat tanah & $500 \mathrm{daN}$ \\
\hline Lebar tiang & $2 \mathrm{~m}$ \\
\hline Sumber : PT. PLN Wilayah S2JB
\end{tabular}

Adapun konstruksi tiang yang digunakan ditunjukkan pada gambar berikut :
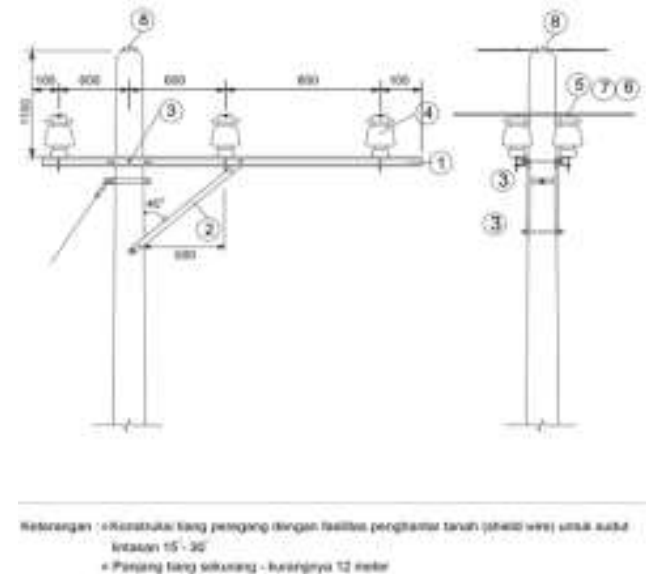

Gambar 8. Konstruksi tiang penumpu sudut kecil dengan kawat tanah [9]

Data spesifikasi tersebut lalu digambarkan mengikuti gambar 2 pada bagian sebelumnya sebagai berikut :

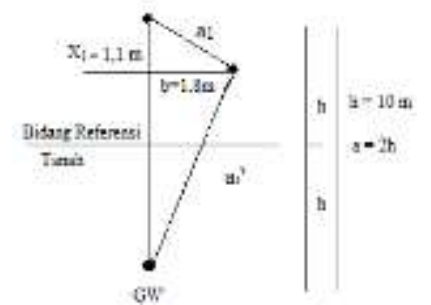

Gambar 7. Jarak antara kawat tanah-kawat fasa-bidang referens berdasarkan data Tabel 1

Berdasarkan gambar 3.(a) dan gambar 8, maka dapat diketahui nilai $\mathrm{b}$ adalah $1,8 \mathrm{~m}$. Dengan menggunakan persamaan (5), (6) dan (4) berturut-turut didapatkan nilai $\mathrm{a}_{1}=$ $1,4 \mathrm{~m}, \mathrm{a}^{\prime}=18,92 \mathrm{~m}$ dan $\mathrm{Z}_{12}=132 \mathrm{ohm}$. Sedangkan nilai $\mathrm{Z}_{22}$ menggunaan persamaan (3) didapat nilai 401,076 ohm.

Selanjutnya Faktor Perisaian dihitung dengan menggunakan persamaan (5) sebagai berikut :

$\mathrm{Z}_{12}=132 \mathrm{ohm}$

$R=20 \mathrm{ohm}$

$\mathrm{Z}_{22}=401,076 \mathrm{ohm}$

$h_{2}=10 \mathrm{~m}$

$h_{1}=8,9 \mathrm{~m}$

Maka,

$$
\begin{aligned}
\mathrm{FP} & =1-\frac{132}{2 \cdot 20+401,076} \cdot \frac{10}{8,9} \\
& =0,664
\end{aligned}
$$

Jumlah kemungkinan gangguan petir akibat sambaran induksi dengan kawat tanah dan tanpa kawat tanah dapat dihitung menggunakan persamaan (7) dan (8). Tingkat ketahanan impuls isolasi $V_{50 \%}$ dari isolator SUTM $20 \mathrm{kV}=$ 160 , sedangkan $\eta$ =adalah 0,5 dan $\mathrm{IKL}=100^{[4]}$, didapat :

- dengan kawat tanah

$$
\begin{aligned}
N_{i}= & 30,6 \cdot 100 \cdot 0,664 \cdot 10 \cdot \frac{e^{-\left(\frac{160}{510 \cdot 0,664} \cdot 10^{0.09}\right)}}{160} \times 0,5 \\
= & 35,50 \text { Gangguan per } 100 \mathrm{~km} \text { pertahun } \\
& -\quad \text { tanpa kawat tanah }
\end{aligned}
$$

$$
\begin{aligned}
N_{i} & =30,6 \cdot 100 \cdot 8,9 \cdot \frac{e^{-\left(\frac{160}{510 \cdot 0,664} \cdot 8,9^{0.09}\right)}}{160} x 0,5 \\
& =47,87 \text { Gangguan per } 100 \mathrm{~km} \text { pertahun }
\end{aligned}
$$

Untuk gangguan petir akibat sambaran langsung probabilitas terjadinya lompatan bunga api menggunakan persamaan 9 dan10 dan jumlah gangguan dengan persamaan 11 didapat:

- tanpa kawat tanah

$$
P_{F L}=e^{-\left(\frac{160}{8,5 \times 401,076}\right)}=0,95
$$

$N_{t}=0,015 \cdot 100 \cdot\left(1,8+4 \cdot 8,9^{1.09}\right) \cdot 0,95 \times 0,5=32,16$

gangguan per $100 \mathrm{~km}$ per tahun

dan,

- dengan kawat tanah

$$
\begin{aligned}
& P_{F L}=e^{-\left(\frac{160}{(10+0,3 \cdot 10) \cdot 34}\right)}=0,7 \\
& N_{t}=0,015 \cdot 100 \cdot\left(0+4 \cdot 9,82^{1.09}\right) \cdot 0,7 \times 0,5=25,33
\end{aligned}
$$

gangguan per $100 \mathrm{~km}$ per tahun

Langkah berikutnya adalah menentukan nilai andongan dari kawat tanah dengan menggunakan persamaan 13. Nilai andongan ini nantinya dipergunakan untuk menghitung tinggi rata-rata kawat tanah, $\mathrm{h}$.

$D=\frac{0,447 \times 50^{2}}{8 \times 500}=0,27$ meter $=27 \mathrm{~cm}$

Tinggi rata-rata kawat tanah,

$h=10-\frac{2}{3} 0,27=9,82$ meter

Daerah perisaian satu kawat tanah berdasarkan persamaan 12 sebesar :

$$
w=0+4 \times 9,82^{1,09}=48,24 \text { meter. }
$$

Jika tanpa kawat tanah,maka daerah perisaiannya adalah :

$$
w=1,8+4 x 8,9^{1,09}=45,14 \text { meter }
$$

Jika mengacu pada gambar 7 , maka sudut perlindungan dari kawat tanah sebesar:

$$
\theta=\sin ^{-1}\left(\frac{b}{a_{1}}\right)=\sin ^{-1}\left(\frac{0,9}{1,4}\right)=40^{\circ}
$$

Berdasarkan gambar 4, nilai sudut yang didapat dari perhitungan menunjukkan bahwa kawat tanah mampu memberikan perlindungan kepada saluran. Hasil-hasil perhitungan dirangkum dalam tabel berikut : 


\begin{tabular}{lcc}
\hline \multicolumn{1}{c}{ Item Perhitungan } & $\begin{array}{c}\text { Tanpa Kawat } \\
\text { Tanah }\end{array}$ & $\begin{array}{c}\text { Dengan Satu } \\
\text { Kawat Tanah }\end{array}$ \\
\hline $\begin{array}{l}\text { Gangguan karena } \\
\text { induksi }\end{array}$ & 47,87 & 35,5 \\
$\begin{array}{l}\text { Gangguan karena } \\
\text { sambaran langsung }\end{array}$ & 32,16 & 25,33 \\
Daerah Perisaian & $45,14 \mathrm{~m}$ & $48,24 \mathrm{~m}$ \\
Faktor Perisaian & - & 0,664 \\
Sudut Perlindungan & - & $40^{\circ}$ \\
\hline
\end{tabular}

Hasil perhitungan menunjukkan bahwa penempatan kawat tanah efektif untuk melindungi SUTM 20 kV GI Boom Baru dengan tinggi tiang JTM dari atas tanah 10 meter. Hal ini dibuktikan dengan terjadinya pengurangan jumlah gangguan induksi sebanyak $25,8 \%$ bila kawat tanah ditempatkan pada jaringan, sedangkan jumlah gangguan sambaran langsung menurun $21,23 \%$. Begitu juga dari daerah perisaian, terdapat peningkatan lebar daerah perisaian sebesar $6,87 \%$.

\section{DAFTAR PUSTAKA}

[1] Z. G. Datsios, P. N. Mikropoulos, and T. E. Tsovilis, "Estimation of the minimum shielding failure flashover current for first and subsequent lightning strokes to overhead transmission lines," Electr. Power Syst. Res., 2014.

[2] P. Sarajcev, "Monte Carlo method for estimating backflashover rates on high voltage transmission lines," Electr. Power Syst. Res., 2015.

[3] S. V. M. Amiri and H. R. Mirazizi, "A new approach to optimal location of single-transformer sub-transmission substations using GIS analysis," 2017 Conf. Electr. Power Distrib. Networks Conf., pp. 156-166, 2017.

[4] M. A. H. Sirad, M. Rais, M. R. Djalal, and A. N. Putri, "Optimization of grounding resistance to minimize transient currents at $150 \mathrm{kV}$ SULSELRABAR system," in 2018 International Conference on Information and Communications Technology, ICOIACT 2018, 2018, vol. 2018-Janua.

[5] M. A. H. Sirad and S. Taha, "Performance Optimazation Of $150 \mathrm{KV}$ Transmission Tower In Jeneponto Steam Power Plant Using GIS Analysis."

[6] M. A. H. Sirad and S. Taha, "Optimasi Kinerja Jaringan Transmisi $150 \mathrm{Kv}$ Menggunakan Simulasi Geographic Information System Akibat Back Flashover Pada Pltu Jeneponto," Patria Artha Technol. J., vol. 2, no. 2, pp. 109-116, 2018.

[7] J. A. Martinez and F. Castro-Aranda, "Lightning flashover rate of an overhead transmission line protected by surge arresters," in Power Engineering Society General Meeting, 2007. IEEE, 2007, pp. 1-6.

[8] T. S. Hutauruk, "Gelombang Berjalan dan Proteksi Surja,” Erlangga, Jakarta, 1989.
[9] P. T. PLN, "Standar Konstruksi Jaringan Tegangan Menengah Tenaga Listrik," Jakarta PT. PLN, 2010.

[10] E. Erhaneli and A. Desril, "Pengaruh Kawat Tanah Terhadap Gangguan Kilat Induksi Pada Sutm 20 Kv," J. Tek. Elektro-ITP, vol. 1, no. 1, 2013. 